\title{
Oocyte control of ovarian follicular development and function in mammals
}

\author{
John J. Eppig \\ The Jackson Laboratory, 600 Main Street, Bar Harbor, ME 04609, USA
}

\begin{abstract}
A new perspective on ovarian follicular development has emerged over the last decade. Whereas the oocyte was previously considered only a passive recipient of developmental signals from oocyte-associated granulosa cells, it is now clear that communication between oocytes and granulosa cells is bidirectional. A complex interplay of regulatory factors governs the development of both types of cell. This interplay is essential not only for oocyte development but also for follicular development, beginning with the initial assembly of the primordial follicle and continuing throughout ovulation. The existence of an oocyte-granulosa cell regulatory loop, essential for normal follicular differentiation as well as for the production of an oocyte competent to undergo fertilization and embryogenesis, is proposed. Although gonadotrophins are essential for driving the differentiation of granulosa cell phenotypes, within its sphere of influence, the oocyte is probably the dominant factor determining the direction of differentiation and the function of the granulosa cells associated with it.
\end{abstract}

It has long been realized that follicular somatic cells support oocyte development. The close physical association of these two types of cell indicated this to early biologists, but physiological evidence was first presented by Pincus and Enzmann (1935), who found that fully grown oocytes removed from antral follicles underwent a spontaneous, gonadotrophin-independent resumption of meiosis in culture, and concluded that follicular somatic cells maintain oocytes in meiotic arrest. Subsequent studies demonstrated that follicular somatic cells promote the reinitiation of meiosis and its progression to metaphase II (nuclear maturation). Follicular somatic cells also promote oocyte competence to undergo fertilization and preimplantation embryogenesis (cytoplasmic maturation) (Buccione et al., 1990a) and granulosa cells participate in the global suppression of transcription in oocytes that occurs before nuclear maturation (Fig. 1) (De la Fuente and Eppig, 2001). In contrast to granulosa cell-to-oocyte communication, knowledge of oocyte-to-granulosa cell communication is relatively recent. The studies of Nalbandov and colleagues pioneered this field, observing a precocious luteinization of rabbit follicles in vivo after removal of the oocyte-cumulus complex (El-Fouly et al., 1970). Similarly, granulosa cells from antral follicles cultured in the absence of oocytes were observed to resemble luteinized granulosa cells, whereas those cultured in the proximity of oocytes appeared to maintain a granulosa cell-like appearance (Nekola and Nalbandov,

Email: jje@jax.org
1971). These authors concluded that oocytes secrete an anti-luteinization factor. However, subsequent studies failed to support this hypothesis, as pig oocytes appeared to have no effect on progesterone production, a hallmark of luteinized cells, by granulosa cells in vitro (Channing and Tsafriri, 1977). This last study had a discouraging effect on further research in this area for more than a decade. However, since 1990, data have emerged showing that oocytes can regulate progesterone production as well as play key roles in controlling granulosa cell development and function from the time of follicular organization and continuing throughout ovulation (Fig. 1).

\section{Co-ordination of oocyte and follicular development}

Soon after oocytes enter a prolonged diplotene stage of meiosis, the dictyate stage, the precursors to the follicular somatic cells encompass the oocyte in a single squamous layer to form primordial follicles. The large population of non-growing primordial follicles serves as the source of developing follicles and oocytes until the end of a female's reproductive life. Until that time, there is a continuous recruitment of follicles from this pool, beginning with the formation of primary follicles. The oocyte in a primary follicle begins its extensive growth phase, and the surrounding follicular cells (now called granulosa cells) become cuboidal and proliferative. When the growing oocytes are surrounded by more than one layer of granulosa cells, the follicle is called a secondary follicle. Although primary and secondary follicular development can take place in the absence of gonadotrophins, these follicles are 


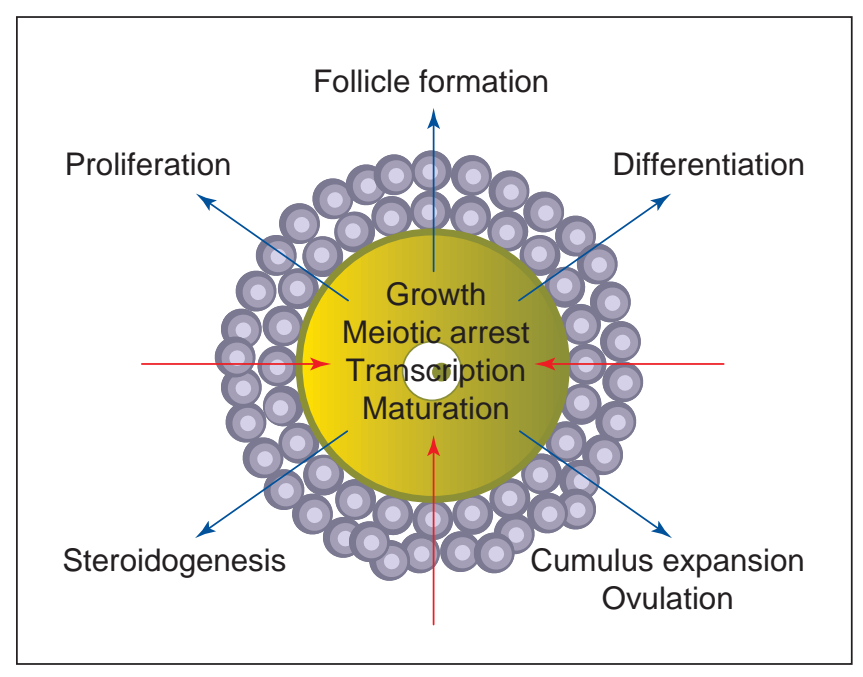

Fig. 1. Bidirectional communication between oocytes and companion somatic cells showing the influences of granulosa cells on oocyte development and the processes in granulosa cells controlled by oocytes.

responsive to gonadotrophins and therefore optimal development of preantral follicles may require these hormones (Fortune and Eppig, 1979; Cortvrindt et al., 1997). The initial signals for the development of a follicular antrum are not well understood, but at some point, cavities form and fill with follicular fluid. Development beyond the early antral follicle stage is clearly dependent upon gonadotrophins; antral follicles are sometimes called tertiary follicles. Well-developed antral follicles are often referred to as Graafian follicles. However, after the preovulatory gonadotrophin surge, they are called preovulatory follicles. The formation of a follicular antrum divides the population of granulosa cells into two main groups: cumulus cells associated with the oocyte and mural granulosa cells lining the follicular wall. The mural granulosa cells nearest the antrum are called periantral granulosa cells.

About the time of transition from preantral to antral follicles, a critical developmental change also takes place in the oocytes. Before antrum formation, oocytes are unable to progress beyond the diplotene stage of meiosis I. These oocytes are therefore referred to as meiotically incompetent, a state that is attributable to an insufficiency in regulatory molecules necessary to drive meiotic progression. However, most oocytes in antral follicles are meiotically competent and will resume meiosis spontaneously if removed from the follicle and cultured in supportive medium (for a review, see Handel and Eppig, 1997). It was this observation that led Pincus and Enzmann (1935) to conclude that follicular somatic cells arrest the progression of meiosis in competent oocytes.

Although oocytes are generally thought to complete their growth phase near the transition from preantral to antral follicles, this is not strictly true. The increase in oocyte diameter during antral follicular growth is relatively small, but the increase in oocyte volume, or mass, is significant. For example, the diameter of oocytes from medium size antral follicles of 18-day-old mice is about $73 \mu \mathrm{m}$, whereas that of oocytes from larger antral follicles of 22-day-old mice is about $76 \mu \mathrm{m}$, representing an increase in diameter of about $4 \%$. However, at the same time, the volume increases by almost 13\% from 203770 to $229940 \mu \mathrm{m}^{3}$ in oocytes from 18- and 22-day-old mice, respectively (Eppig and O'Brien, 1996). Nevertheless, the large oocytes isolated from gonadotrophin-primed 22-24-day-old mice will be referred to here as 'fully grown'.

Oocytes continue to grow after they acquire competence to resume meiosis. Nevertheless, oocytes competent to resume meiosis are not necessarily competent to undergo complete nuclear maturation and progress to metaphase II. Oocytes isolated from small antral follicles are competent to undergo germinal vesicle breakdown (GVBD) and progress to metaphase I, but the progression of meiosis in these oocytes usually becomes arrested at this stage. Therefore, further development of oocytes in antral follicles is required for oocytes to become competent to progress to metaphase II (Handel and Eppig, 1997).

The preovulatory surge of gonadotrophins induces marked changes in both the follicle and the oocytecumulus cell complex. Oocytes resume meiosis and progress to metaphase II before ovulation in most, but not all, mammals that have been studied. As oocytes mature in response to the preovulatory gonadotrophin surge, cumulus cells secrete hyaluronic acid, a non-sulphated glycosaminoglycan bound to the cumulus cells by linker proteins (Eppig, 1979; Salustri et al., 1989; Chen et al., 1996). When the hyaluronic acid becomes hydrated, spaces between cumulus cells become enlarged, and the cells become embedded in a sticky, mucified matrix. Hence, this process is called cumulus expansion or mucification. If cumulus expansion is suppressed, ovulation rate is greatly reduced (Chen et al., 1993). Thus, cumulus expansion is one of several important processes that must occur in preovulatory follicles to enable ovulation. The mural granulosa cells remaining within the ovary undergo further differentiation and luteinization. These cells together with theca cells subsequently form the corpus luteum, which is essential for the maintenance of pregnancy.

It would be difficult to imagine that the highly coordinated development of the oocyte and somatic cell compartments of ovarian follicles could occur without constant intercommunication between the cell types. What follows is not only a summary of progress in the discovery of the role of oocytes in affecting the differentiation and function of granulosa cells, but also a presentation of the hypothesis that there is an oocyte-granulosa cell regulatory loop. Signals exchanged within this loop are thought to be essential for inducing and co-ordinating the differentiation of both the oocyte and somatic compartments from one developmental stage to the next (Fig. 2). 


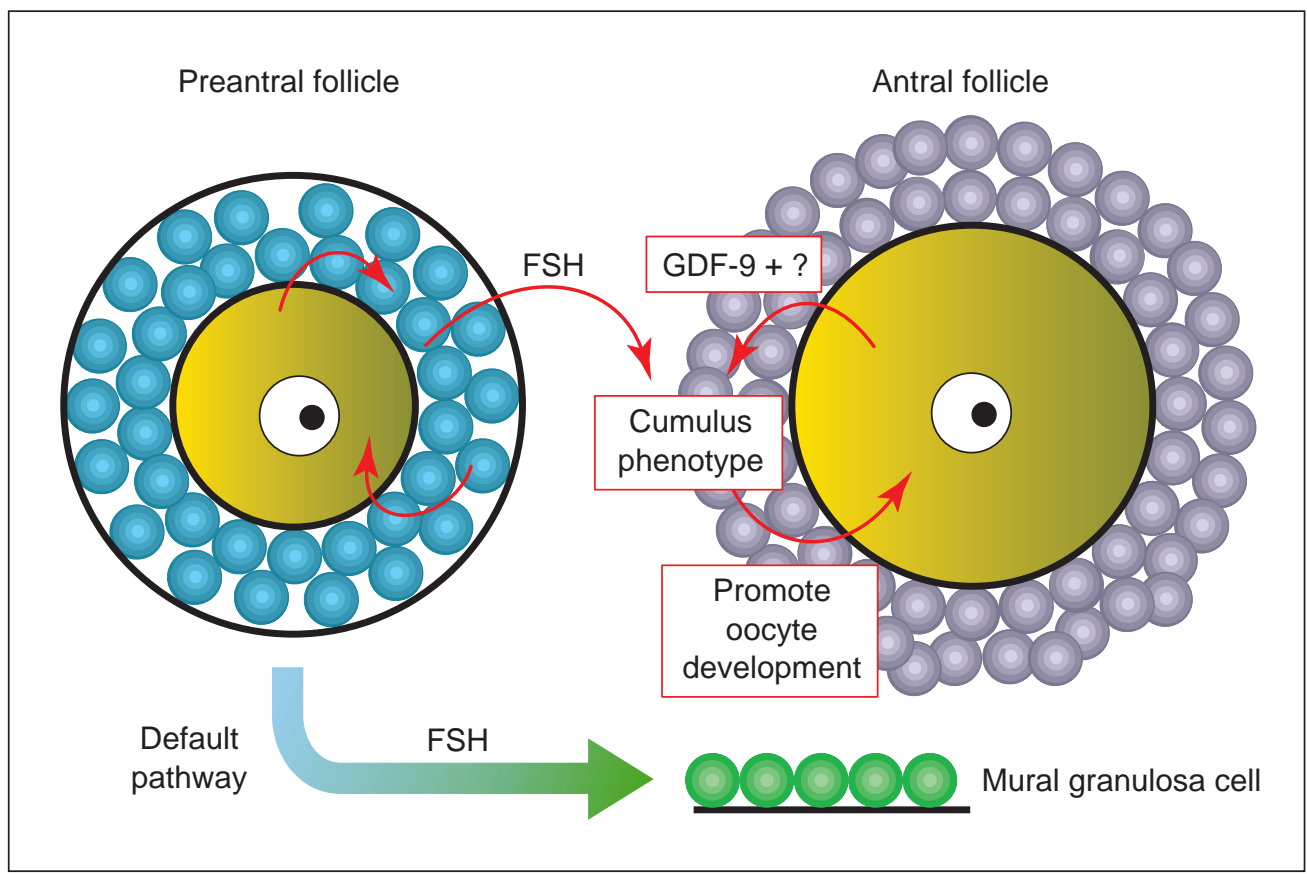

Fig. 2. Hypothesized oocyte-granulosa cell regulatory loop and its possible function during the transition from preantral to antral follicles. At this stage of follicular development, factors from granulosa cells, such as Kit Ligand, promote oocyte development, whereas factors from the oocyte influence granulosa cell development and function. These interactions, in concert with gonadotrophins and other factors, promote the transition to antral follicular development. In antral follicles, oocytederived factors, such as growth differentiation factor 9 (GDF-9), promote the development of the cumulus cell phenotype by suppressing expression of the mural granulosa cell phenotype. Without the influence of these factors from oocytes, mural granulosa cells differentiate as the default programme. The cumulus cell phenotype, promoted by GDF-9 and probably other factors as well, is essential for promoting the development of oocytes competent to undergo fertilization and embryogenesis.

\section{Role of the oocyte in follicular development}

\section{Primordial follicle formation}

Oocytes are essential for follicular formation; without oocytes, follicles are not assembled. This contrasts with the formation of the male homologue, the seminiferous tubule, which can form in the absence of spermatocytes. Although little is known regarding the mechanisms of follicular formation, at least one oocyte-expressed gene is required for this process. Figla (also known as Fig $\alpha$ ) is a gene encoding a helix-loop-helix transcription factor that co-ordinates the expression of the structural genes for components of the zona pellucida. Expression of Figla mRNA begins as early as embryonic day 13 in mice, more than a week before zona pellucida genes are expressed in oocytes. Moreover, primordial follicles do not form after mutation of Figla by homologous recombination (Soyal et al., 2000). Thus, Figla appears to regulate at least two important pathways in oocytes, although the relationship between these pathways is not obvious. One pathway co-ordinates the production of zona pellucida proteins, and the other regulates the production of one or more factors by the oocyte that are essential for the initial organization of primordial follicles. This factor might be a secreted chemotactic factor that summons the prefollicular somatic cells to the oocyte, or a surface adhesion molecule that establishes and maintains contact with appropriate somatic cells. It remains a matter of speculation whether the follicular organization pathway remains functional during subsequent oocyte-follicular development when the zona pellucida is produced.

\section{Early follicular development}

Although the mechanisms for selecting and activating primordial follicles for entry into the cohort of developing follicles are not known, the oocyte clearly plays a key role in development beyond the primary follicle stage. Growth differentiation factor 9 (GDF-9) is an oocyte-specific member of the TGF $\beta$ family produced by mouse, cow, sheep, rat and human oocytes (McGrath et al., 1995; Laitinen et al., 1998; Aaltonen et al., 1999; Bodensteiner et al., 1999). Thus, GDF-9 is probably a paracrine regulatory factor produced by all mammalian oocytes. It is expressed 
by oocytes throughout ovulation. In mice, expression by oocytes begins in primary follicles, whereas in other species, it is also expressed by primordial oocytes. Mutation of the Gdf9 gene by homologous recombination in mice does not prevent recruitment of primordial follicles to the primary stage. However, further development of the somatic cells beyond the primary follicle stage fails in Gdf9null mice (Dong et al., 1996). Nevertheless, the oocytes continue to grow, at an accelerated rate, and oocyte morphology eventually becomes abnormal (Carabatsos et al., 1998). Granulosa cell expression of the Kitl gene, encoding Kit Ligand $(\mathrm{KL}) \mathrm{mRNA}$, appears to be increased in follicles of Gdf9-null mice (Elvin et al., 1999b), and KL is thought to promote oocyte growth or development, or both (Packer et al., 1994; Reynaud et al., 2000). This finding indicates that GDF-9 suppresses Kitl expression in granulosa cells. Indeed, recombinant GDF-9 does suppress Kitl expression by granulosa cells isolated from both preantral and antral follicles (Joyce et al., 2000). However, when these groups of granulosa cells were co-cultured with either medium-sized oocytes from preantral follicles or with fully grown oocytes from antral follicles, only the fully grown oocytes were able to suppress Kitl expression by either group of granulosa cells. The medium-sized oocytes either had no effect or a slightly stimulatory effect on Kitl expression by preantral granulosa cells in vitro. Removal of the fully grown oocyte (oocytectomy) from oocyte-cumulus cell complexes isolated from antral follicles resulted in increased Kitl expression, which was suppressed by co-culture with fully grown oocytes (Joyce et al., 2000). Thus, the regulation of Kitl expression in the primary follicles of Gdf9-null mice seems more similar to the regulation of Kitl expression in the oocyte-cumulus cell complex of antral follicles than would be expected in normal preantral follicles. However, this issue is probably more complicated since the concentration of FSH in Gdf9-null mice is increased (Dong et al., 1996) and FSH alone promotes Kitl expression by preantral granulosa cells but not by granulosa cells from antral follicles (Joyce et al., 1999).

Assuming that GDF-9 from fully grown oocytes suppresses Kitl expression by cumulus cells, and that KL may promote oocyte growth, an oocyte-granulosa cell regulatory loop that affects oocyte growth can be postulated. In this model, KL produced by granulosa cells of preantral and early antral follicles would promote oocyte growth until a species-specific size is reached. At this point, GDF-9 secreted by oocytes would suppress Kitl expression in cumulus cells, which would slow or terminate oocyte growth. It is not known why GDF-9 from medium-sized oocytes does not suppress Kitl expression. Perhaps GDF-9 secretion is not constitutive by medium-sized oocytes, but instead is regulated by granulosa cells. Alternatively, GDF-9 may be secreted in an inactive form by medium-sized oocytes, or certain factors from these oocytes may inhibit its action. However, preantral follicular granulosa cells clearly respond to recombinant GDF-9 and to factors from fully grown oocytes in suppressing Kitl expression, although the role of $\mathrm{KL}$ in promoting oocyte growth remains controversial. FSH markedly stimulates Kitl expression in preantral follicular granulosa cells, yet oocytes grow in the absence of FSH. Moreover, oocytes appear to grow in animals treated with neutralizing antibodies to $\mathrm{KL}$ despite clear effects of these antibodies on follicular development (Yoshida et al., 1997). These effects are probably mediated by interstitial cells that, in addition to oocytes, also express KIT receptors. However, evidence indicates that KL plays some role in oocyte growth. Under some experimental conditions, KL treatment in vitro appears to accelerate oocyte growth (Packer et al., 1994), and some mutant Kitl alleles, for example KitlIl-pan (Huang et al., 1993; Bedell et al., 1995), cause both decreased oocyte growth and follicular development. However, the results of other studies in vitro do not support a role for KL in oocyte growth, but indicate that $\mathrm{KL}$ promotes oocyte survival and cytoplasmic maturation (Reynaud et al., 2000). Nevertheless, expression of $\mathrm{KL}$ by granulosa cells, and its receptor by oocytes, strongly implies a functional relationship of some kind. This observation, together with the clear ability of oocytes to regulate Kitl expression, probably via GDF-9, reveals a complex oocyte-granulosa cell regulatory loop.

Another member of the TGF $\beta$ family, Bmp15, also known as GDF-9B, exhibits an expression pattern similar to that of Gdf9 (Dube et al., 1998; Jaatinen et al., 1999; Elvin et al., 2000b; Otsuka et al., 2000). Homozygosity of a natural mutation in sheep $\left(F e c X^{\prime} / F e c X^{l}\right)$ results in sterility due to failure to develop beyond the primary stage (Davis et al., 1992; Galloway et al., 2000), similar to that observed in Gdf9-null mice (Dong et al., 1996). Fec $X^{\prime}$ is homologous to Bmp15 (Galloway et al., 2000). Thus, BMP15 protein produced by oocytes is critically important for early follicular development in sheep. Fec $X^{\prime} / F e c X^{+}$heterozygotes exhibit increased ovulation rate with a high incidence of twin and triplet births (Davis et al., 1992). The mechanisms involved in the augmentation of follicular development and ovulation due to the presumed $50 \%$ production of normal BMP15 protein are not known. One explanation is that feedback mechanisms between the ovary and pituitary are affected by the reduced expression of BMP15, resulting in increased gonadotrophin signalling and, consequently, augmented follicular development (Galloway et al., 2000). If so, this would show that oocyte-derived factors have profound indirect effects on the dynamics of follicular recruitment via systemic mechanisms.

A null mutation of Bmp15 induced in mice does not exhibit the same ovarian phenotype as that in $F e c X^{\prime} / F e c X^{\prime}$ sheep (Yan et al., 2001). Although fertility in Bmp15-null female mice is reduced, the morphology of follicular development appears essentially normal (Yan et al., 2001); there is no arrest of early follicular development as seen in Fec $X^{I} / F_{e c} X^{I}$ sheep. Nevertheless, double mutant female mice homozygous for the Bmp15-null allele and heterozygous for the Gdf9-null allele exhibit more severe fertility defects than do the single mutant Bmp15-null females. Moreover, the percentage of fertilized oocytes found in the 
oviducts after superovulation and mating was markedly reduced (Yan et al., 2001). Thus, synergism between Gdf9 and Bmp15 is required for normal follicular and oocyte development in mice. It is possible that BMP-15 and GDF-9 proteins play similar functional roles in early follicular development, but BMP-15 may be more important in sheep than it is in mice.

\section{Oocyte regulation of granulosa cell development}

\section{Proliferation}

Fully grown oocytes probably promote the proliferation of granulosa cells via the secretion of one or more paracrine factors (Vanderhyden et al., 1992; Lanuza et al., 1998; Li et al., 2000). This would account, at least in part, for the heterogeneous pattern of proliferation in which granulosa cells nearest the oocyte were observed to multiply more rapidly than distal granulosa cells (Hirshfield, 1986). Bovine oocytes rapidly lose mitogenic capability during oocyte maturation (Lanuza et al., 1998), whereas medium-sized mouse oocytes appear to have not yet developed this capability (Gilchrist et al., in press). Thus, the ability of oocytes to regulate granulosa cell proliferation appears to be developmentally regulated. Since recombinant GDF-9 and BMP-15 promote the proliferation of granulosa cells from small antral follicles (Hayashi et al., 1999; Otsuka et al., 2000; Vitt et al., 2000), GDF-9 and BMP-15 are probably oocyte-derived mitogens. However, as described above, the mechanisms whereby oocytes regulate granulosa cell proliferation are complex, and involve multiple factors. Moreover, it seems likely that the regulation of granulosa cell proliferation is part of a larger mechanism of oocyte control over the development and function of the associated granulosa cell population.

\section{Differentiation}

Formation of the follicular antrum effectively establishes the basis for a morphological definition of two granulosa cell populations: the mural granulosa cells associated with the follicular wall, and the cumulus cells associated with the oocyte. With advancing follicular development, which is driven by gonadotrophins and aided by various intrafollicular regulators, these populations can be distinguished in molecular as well as morphological terms. For example, cumulus cells express few, if any, LH receptors (LHR). In contrast, mural granulosa cells express these receptors and the highest expression is observed in cells that are in close apposition to the basal lamina (Amsterdam et al., 1975). In fact, components of basal lamina augment gonadotrophininduced expression of LHR (a product of the Lhcgr gene) (Furman et al., 1986; Eppig et al., 1997a). This pattern of gene expression is quite common and includes the expression of Kitl (Manova et al., 1993; Motro and Bernstein, 1993; Joyce et al., 1999). Oocytes play a key role in the establishment of this heterogeneous pattern of gene expression by granulosa cells. Microsurgical extirpation of the oocyte from isolated oocyte-cumulus cell complexes promotes expression of both Lhcgr and Kitl. This increased expression is prevented by paracrine factors secreted by oocytes (Eppig et al., 1997a; Joyce et al., 1999). Thus, one or more factors secreted by the oocyte probably reduce the expression by cumulus cells of genes characteristic of the mural granulosa cell phenotype.

Oocytes also suppress expression of Lhcgr by mural granulosa cells in vitro. Fully grown oocytes prevent the FSHinduced increase in Lhcgr mRNA production by granulosa cells in vitro, after isolation from small antral follicles. Moreover, oocytes suppress Lhcgr mRNA in granulosa cells, expressing large amounts of Lhcgr mRNA when isolated from large antral follicles of gonadotrophin-stimulated females (Eppig et al., 1997a). Thus, oocytes play a dominant role in the regulation of $L$ hcgr expression. Therefore, it appears that the default pathway of gonadotrophin-stimulated granulosa cell differentiation leads to the expression of a mural granulosa cell-like phenotype, at least insofar as Lhcgr expression is representative of this phenotype. Nevertheless, oocytes can abrogate this pathway of differentiation and promote a phenotype more typical of cumulus cells. Studies on Kitl expression produce similar results. However, oocytes are somewhat less able to suppress the expression of Kitl, stimulated by testosterone and FSH in mouse granulosa cells, than they are able to suppress expression of Lhcgr (Joyce et al., 1999). GDF-9 mimics the actions of fully grown oocytes in suppressing the expression of Lhcgr and Kitl mRNA (Elvin et al., 1999a; Joyce et al., 2000). This finding supports the hypothesis that the actions of oocytes in regulating transcription of these genes are mediated by GDF-9. However, paradoxically, medium-sized oocytes have little or no ability to suppress Lhcgr or Kitl mRNA expression in granulosa cells despite expression of both GDF-9 mRNA and protein in these oocytes. More studies are needed to define the interactive roles of gonadotrophins, intrafollicular paracrine and autocrine factors, extracellular matrix components and oocytes in promoting the complex patterns of gene activity that completely define the cumulus and mural granulosa cell phenotypes.

In granulosa cells, luteinization is a terminal differentiative process that normally takes place during the periovulatory period. Nalbandov and colleagues suggested that oocytes produce an anti-luteinizing factor that prevents untimely terminal differentiation (El-Fouly et al., 1970; Nekola and Nalbandov, 1971). Progesterone production is one of the hallmarks of luteinization. Although there are many other parameters of luteinization (Richards et al., 1995), oocytes clearly affect the differentiation of granulosa cells in ways that suppress progesterone production before the LH surge, thus supporting the Nalbandov hypothesis. FSH stimulates progesterone production by oocytectomized complexes after isolation of oocyte-cumulus cell complexes from antral follicles. This progesterone production is suppressed by factors secreted by fully grown oocytes (Vanderhyden et al., 1993; Coskun et al., 1995; Vanderhyden and Tonary, 1995; Li et al., 2000). Coincident with the 
suppression of progesterone production, mouse oocytes promote oestrogen production. These two actions of oocytes on steroidogenesis appear independent of each other and occur downstream of FSH stimulation of increased CAMP (Vanderhyden and Tonary, 1995). The granulosa cells of preantral follicles also produce progesterone in response to $\mathrm{FSH}$, and this steroid production is inhibited by mediumsized oocytes. Ovulated mature oocytes can also suppress progesterone production by cumulus cells, but only those cumulus cells isolated before the induction of ovulation. Cumulus cells from complexes recovered from oviducts appear refractory to the oocyte factors that suppress progesterone production. Thus, the progesterone-productionsuppressing factor is produced by all stages of oocytes tested, from medium-sized through to mature ovulated oocytes. However, gonadotrophin-induced cumulus cell differentiation makes these cells refractory to the oocytederived factors (Vanderhyden and Macdonald, 1998). Therefore, although oocyte-derived factors can prevent precocious luteinization, once this process is initiated, the relevant oocyte factors apparently become superfluous. The identity of the oocyte-derived regulators of steroidogenesis are unknown but appear to be of low molecular weight and heat stabile (Vanderhyden, 1996). Recombinant GDF-9 stimulates progesterone production by granulosa cells (Elvin et al., 1999a) and, therefore, is probably not the oocytederived factor regulating steroidogenesis by cumulus cells before the preovulatory LH surge. Nevertheless, BMP-15 suppresses $\mathrm{FSH}$-induced production of progesterone by granulosa cells (Otsuka et al., 2000), although it is too large to be the same oocyte-derived factor described by Vanderhyden (1998).

\section{Role of the oocyte in ovulation}

\section{Cumulus expansion}

The preovulatory surge of gonadotrophins induces a cascade of processes culminating in ovulation. One of the most marked of these processes is cumulus expansion, or mucification. Gonadotrophins promote cumulus cell production of hyaluronic acid, a non-sulphated glycosaminoglycan that binds to the cumulus cells and expands the spaces between the cells, embedding them in a mucinous matrix. This process is important for ovulation, as inhibiting hyaluronic acid synthesis or linking to cumulus cells in vivo reduces ovulation rates markedly (Chen et al., 1993; Hess et al., 1999). Oocytectomy of oocyte-cumulus cell complexes isolated from mouse follicles prevents $\mathrm{FSH}$-induced hyaluronic acid synthesis by the cumulus cells, but coculture of FSH-stimulated oocytectomized complexes with denuded fully grown oocytes enables expansion of the oocytectomized complex (Buccione et al., 1990b). Similarly, denuded oocytes promote synthesis of hyaluronic acid by FSH-stimulated cultured mural granulosa cells (Salustri et al., 1990). Thus, fully grown oocytes secrete a cumulus expansion-enabling factor (CEEF) that enables granulosa cells to respond to FSH by producing hyaluronic acid. Medium-sized oocytes from preantral follicles do not secrete active CEEF; co-culture of these oocytes with $\mathrm{FSH}$ stimulated oocytectomized complexes from antral follicles does not promote expansion. Although ovulated metaphase II oocytes secrete some active CEEF, this activity is low relative to fully grown GV-stage oocytes, and no CEEF activity is detected by the two-cell stage (Vanderhyden et al., 1990). Thus, secretion of active CEEF by mouse oocytes is developmentally regulated.

Oocytectomy does not prevent expansion of rat, pig or cow cumulus cells (Prochazka et al., 1991; Vanderhyden, 1993; Ralph et al., 1995). However, fully grown oocytes from these species produce CEEF, even though it appears unnecessary to promote expansion, since co-culture of these oocytes with FSH-stimulated oocytectomized mouse complexes results in expansion (Singh et al., 1993; Vanderhyden, 1993; Ralph et al., 1995). Presumably, CEEF produced by rat, pig and cow oocytes is required to promote some function of granulosa cells other than hyaluronic acid synthesis. In fact, pig oocytes appear to secrete a factor that promotes binding of hyaluronic acid within the complex, even though the actual production of hyaluronic acid occurs independently of oocytes (Nagyova et al., 2000). Moreover, pig cumulus cells apparently secrete a factor, similar in activity to oocyte-produced CEEF, which promotes expansion of mouse FSH-stimulated oocytectomized mouse complexes (Prochazka et al., 1998). However, whether this factor is the same as the CEEF produced by the oocyte has yet to be determined.

Recombinant GDF-9 stimulates the expansion of oocytectomized mouse complexes and induces the expression of hyaluronan synthase 2 (Has2) by isolated granulosa cells without stimulation by FSH (Elvin et al., 1999a). Therefore, it seems probable that GDF-9 and CEEF are identical. However, it is important to be mindful of an apparent paradox similar to that described above. If GDF-9 is the factor that suppresses expression of Lhcgr and Kitl by cumulus cells before the preovulatory LH surge, why does it not promote untimely expression of Has2 and cumulus expansion before the surge? Perhaps other factors mediate granulosa cell responsiveness to GDF-9 before or after the surge. It is also possible that responses to GDF-9 are dependent upon the amount of stimulation, and that the amounts of GDF-9 released by oocytes are modulated by theca or granulosa cells in vivo. Thus, small amounts of GDF-9 may suppress $\mathrm{LhgCr}$ and Kitl expression before the surge, whereas larger amounts promote expression of Has2 and cumulus expansion after the surge. Fully grown GVstage oocytes appear to secrete CEEF constitutively, but this may not be the mode of CEEF or GDF-9 secretion in vivo. Before the LH surge, granulosa cells may secrete only small amounts of GDF-9. However, in response to the ovulatory stimulus, the somatic cells may signal the oocytes to release a bolus of GDF-9, launching the preovulatory cascade of cumulus cell processes essential for ovulation. This mechanism would constitute an oocyte-somatic cell 
regulatory loop in which the direction of function is altered by the imposition of ovulation-promoting gonadotrophic signals mediated by the somatic cells.

\section{Ptgs2 expression}

Targeted mutation of the prostaglandin-endoperoxide synthase 2 gene (Ptgs2, also known as Cox2) results in a greatly diminished rate of ovulation in mice (Lim et al., 1997). Thus, production of prostaglandins is required for normal ovulation. The pattern of Ptgs 2 gene expression in mouse preovulatory follicles is complex. Within $2 \mathrm{~h}$ after hCG treatment, expression is observed in mouse mural granulosa cells but not in cumulus cells. By $4 \mathrm{~h}$ after hCG treatment, expression is seen in both cumulus and mural granulosa cells. However, expression is limited to the cumulus cells by $8 \mathrm{~h}$ after hCG treatment. Nevertheless, high expression is seen again in both types of cell by $12 \mathrm{~h}$ after hCG treatment. Thus, the pattern of expression in mural granulosa cells appears multiphasic: first an increase, then a decrease, and then another increase just before ovulation (Joyce et al., 2001). Paracrine factors from oocytes augment expression of Ptgs 2 mRNA steady state concentrations in both cumulus and mural granulosa cells in vitro. However, the second increase in expression in the mural granulosa cells is not observed in vitro unless components of the follicular wall are co-cultured with the isolated mural granulosa cells (Joyce et al., 2001). Thus, the complex pattern of Ptgs 2 mRNA expression during the preovulatory period is probably orchestrated by non-oocyte factors, possibly derived from theca-interstitial cells, but the concentrations are augmented by oocytes. Therefore, oocytes probably affect granulosa cell functions in ways essential for ovulation by promoting prostaglandin production as well as cumulus expansion.

Recombinant GDF-9 stimulates expression of Ptgs2 by granulosa cells in vitro and therefore participates in prostaglandin production (Elvin et al., 1999a). GDF-9 also stimulates expression of Ptgerep2, the EP2 receptor of $\mathrm{PGE}_{2}$ (Elvin et al., 2000a). This pathway appears essential for promoting cumulus cell progesterone production during the periovulatory period (Elvin et al., 2000a). Taken together, these findings indicate that GDF-9 is instrumental in inducing the expression of Has2, Ptgs2 and Ptgerep2 by cumulus cells after the $\mathrm{LH}$ surge and that, in addition to promoting normal ovulation, it is key to the expression of the cumulus cell phenotype during the periovulatory period.

\section{Disassembly of the ovulated oocyte-cumulus cell complex}

The preovulatory gonadotrophin surge stimulates oocyte maturation and cumulus expansion. Before the preovulatory surge, oocytes suppress cumulus cell expression of urokinase plasminogen activator (Plau or uPA), a serine protease involved in tissue remodelling (Canipari et al., 1995). However, cumulus cells in the oviduct express Plau and the mature oocytes secrete tissue type plasminogen activator (tPA), a product of the Plat gene. Ovulated cumulus cells are insensitive to suppression of Plau expression by oocytes (D'Alessandris et al., 2001). Thus, oocytes suppress what would be an inappropriate activation of UPA before the preovulatory LH surge, but participate in the degradation of the cumulus matrix after ovulation.

\section{Conclusions}

A new perspective on ovarian follicular development has emerged over the last decade. As reviewed here, oocytes play an essential role in the development of ovarian follicles beginning with initial follicular formation and ending with the disassembly of the ovulated cumulus-oocyte complex. A complex interplay of regulatory factors governs the development of both the oocyte and the follicle, termed the oocyte-granulosa cell regulatory loop in this review. Although gonadotrophins most likely affect the function of this loop by driving the pathways of granulosa cell differentiation, within its sphere of influence, the oocyte is probably the dominant factor determining the direction of differentiation and the function of the granulosa cells associated with the oocyte. It is proposed that if the oocyte were hypothetically absent from the follicle, gonadotrophins and factors from the theca cells would drive the development of all granulosa cells toward the mural granulosa cell phenotype and ultimate luteinization. Thus, the mural granulosa cell phenotype is the 'default' pathway of granulosa cell development. However, oocytes can abrogate this default pathway and promote the development of the cumulus cell phenotype. In association with the oocyte, gonadotrophins probably also drive the development of the cumulus cell pathway, since oocyte-associated granulosa cells do not gain the ability to undergo cumulus expansion in vitro in the absence of FSH (Eppig, 1991).

Nourishment and signals from companion granulosa cells are essential to support oocyte development. Therefore, as proposed by early investigators, granulosa cells fulfil a role as nurse cells. It now appears that the signals from granulosa cells are complex, and it is possible that they must be presented to the oocyte in a way that is co-ordinated with both oocyte and granulosa cell differentiation. The central organizer that co-ordinates these signals may be the oocyte itself. Cultured granulosa cells from preantral follicles promote the growth of medium-sized oocytes also isolated from preantral follicles. However, fully grown oocytes appear to suppress the ability of preantral granulosa cells to promote oocyte growth. Moreover, granulosa cells of preantral follicles do not promote the further growth of oocytes from antral follicles (Cecconi and Rossi, 2001). Thus, there appears to be a complex regulatory loop controlling granulosa cell-dependent oocyte growth. When oocytes reach a size threshold, they suppress the ability of granulosa cells to promote oocyte growth. Although oocytes from antral follicles suppress the ability of preantral granulosa cells to promote oocyte growth, these fully grown 
oocytes, but not growing oocytes, promote granulosa cell proliferation and therefore the growth of the follicle (Gilchrist et al., in press). Thus, via the oocyte-granulosa cell regulatory loop, the oocyte orchestrates its own growth as well as that of the follicle.

Appropriate cumulus cell differentiation appears to be required for normal oocyte development. Inappropriate, or ambiguous, differentiation of oocyte-associated granulosa cells in vitro is correlated with the formation of oocytes lacking competence to complete preimplantation development (Eppig et al., 1998; Latham et al., 1999). Thus, there might be functions of mural granulosa cells antagonistic to normal oocyte development. Therefore, oocytes probably evolved to produce factors that both prevent the differentiation of granulosa cells expressing the mural granulosa cell phenotype and promote the cumulus cell phenotype. The specific attributes of either the phenotype of mural granulosa cells that are potentially antagonistic to oocyte development, or of the phenotype of cumulus cells that are beneficial to oocyte development, are unknown. However, the proposed oocyte-granulosa cell regulatory loop is probably essential for the progression of normal development in both the oocyte-associated granulosa cells and the oocyte. Therefore, this loop is key to successful follicular development.

Besides organizing and co-ordinating granulosa cell differentiation and function on its own behalf, the oocyte appears to play a role in its own delivery to the site of fertilization, the oviduct. Ovulation requires cumulus expansion and prostaglandin production, and factors secreted by oocytes participate in both of these processes, and possibly others as well. Moreover, the finding of increased fecundity in $\mathrm{Fec}^{\prime} / \mathrm{Fec} \mathrm{X}^{+}$heterozygous sheep indicates that oocytes have an indirect influence on follicular dynamics mediated by modulation of negative feedback mechanisms controlling gonadotrophin concentrations. Thus, the impact of the oocyte on reproductive processes extends beyond the boundaries of its own microenvironment.

Factors participating in the oocyte-granulosa cell regulatory loop, in addition to GDF-9, BMP-15 and $\mathrm{KL}$, are being investigated. Although GDF-9 and BMP-15 are not the only important oocyte-derived factors, they appear to be critical for determining the preovulatory phenotype of cumulus cells. Metabolic labelling and detection of oocyte secretory proteins after separation by two-dimensional polyacrylamide gel electrophoresis reveals many individual proteins as well as proteins with complex post-translational modifications (Eppig et al., 1997b). An important challenge for the future will be to characterize these proteins, in addition to non-proteinaceous oocyte-derived factors. This will not be a simple task, as these regulators are produced in minute quantities, and a variety of molecular technologies will be required for their detection and characterization. Moreover, discovery and identification are only the beginning. Resolution of function will require genetic modification, production of recombinant proteins, antibodies, blocking agents, and implementation of imaginative cell culture techniques. Success in these tasks will generate exciting new knowledge of fundamental mechanisms that govern the development of both oocyte and somatic components of follicles, as well as a plethora of new targets for fertility control.

Research on the control of granulosa cell development and function by oocytes carried out in the author's laboratory is supported by grants from the National Institute of Child and Human Development (HD23839 and HD21970). The author thanks leuan Joyce, Martin Matzuk, Robert Taft, Barbara Vanderhyden, and Maria Viveiros for their comments on the manuscript; Martin Matzuk and Antonietta Salustri for providing preprints of their papers in press; Robin Barstow and Elizabeth Kensler for editorial help; and Jen Smith for assistance in the preparation of graphics.

\section{References}

Key references are identified by asterisks.

Aaltonen J, Laitinen MP, Vuojolainen K et al. (1999) Human growth differentiation factor 9 (GDF-9) and its novel homolog GDF-9B are expressed in oocytes during early folliculogenesis Journal of Clinical Endocrinology and Metabolism 84 2744-2750

Amsterdam A, Koch Y, Lieberman ME and Lindner HR (1975) Distribution of binding sites for human chorionic gonadotropin in the preovulatory follicle of the rat Journal of Cell Biology 67 894-900

Bedell MA, Brannan CI, Evans EP, Copeland NG, Jenkins NA and Donovan PJ (1995) DNA rearrangements located over $100 \mathrm{~kb} 5^{\prime}$ of the Steel (Sl)coding region in Steel-panda and Steel-contrasted mice deregulate SI expression and cause female sterility by disrupting ovarian follicle development Genes and Development 9 455-470

Bodensteiner KJ, Clay CM, Moeller CL and Sawyer HR (1999) Molecular cloning of the ovine growth/differentiation factor-9 gene and expression of growth/differentiation factor-9 in ovine and bovine ovaries Biology of Reproduction $60381-386$

Buccione R, Schroeder AC and Eppig JJ (1990a) Interactions between somatic cells and germ cells throughout mammalian oogenesis Biology of Reproduction 43 543-547

*Buccione R, Vanderhyden BC, Caron PJ and Eppig JJ (1990b) FSH-induced expansion of the mouse cumulus oophorus in vitro is dependent upon a specific factor(s) secreted by the oocyte Developmental Biology 138 $16-25$

Canipari R, Epifano O, Siracusa G and Salustri A (1995) Mouse oocytes inhibit plasminogen activator production by ovarian cumulus and granulosa cells Developmental Biology 167 371-378

*Carabatsos MJ, Elvin J, Matzuk MM and Albertini DF (1998) Characterization of oocyte and follicle development in growth differentiation factor-9-deficient mice Developmental Biology 204 373-384

Cecconi S and Rossi G (2001) Mouse antral oocytes regulate preantral granulosa cell ability to stimulate oocyte growth in vitro. Developmental Biology 233 186-191

Channing CP and Tsafriri A (1977) Lack of an inhibitory influence of oocytes upon luteinization of porcine granulosa cells in culture Journal of Reproduction and Fertility 50 103-105

Chen L, Russell PT and Larsen WJ (1993) Functional significance of cumulus expansion in the mouse: roles for the preovulatory synthesis of hyaluronic acid within the cumulus mass Molecular Reproduction and Development 34 87-93

Chen L, Zhang H, Powers RW, Russel PT and Larsen WJ (1996) Covalent linkage between proteins of the inter- $\alpha$ inhibitor family and hyaluronic acid is mediated by a factor produced by granulosa cell Journal of Biological Chemistry 27119 409-19414

Cortvrindt R, Smitz J and VanSteirteghem AC (1997) Assessment of the 
need for follicle stimulating hormone in early preantral mouse follicle culture in vitro. Human Reproduction 12 759-768

Coskun S, Uzumcu M, Lin YC, Friedman CI and Alak BM (1995) Regulation of cumulus cell steroidogenesis by the porcine oocyte and preliminary characterization of oocyte-produced factor(s) Biology of Reproduction 53 670-675

*D'Alessandris C, Canipari R, Di Giacomo M, Epifano O, Camaioni A, Siracusa G and Salustri A (2001) Control of mouse cumulus cell-oocyte complex integrity before and after ovulation: plasminogen activator synthesis and matrix degradation Endocrinology 142 3033-3040

Davis GH, McEwan JC, Fennessy PF, Dodds KG, McNatty KP and O W-S (1992) Infertility due to bilateral ovarian hypoplasia in sheep homozygous (FecX1 FecX1) for the inverdale prolificacy gene located on the X chromosome Biology of Reproduction 46 636-640

De la Fuente R and Eppig JJ (2001) Transcriptional activity of the mouse oocyte genome: companion granulosa cells modulate transcription and chromatin remodeling Developmental Biology 229 224-236

*Dong JW, Albertini DF, Nishimori K, Kumar TR, Lu NF and Matzuk MM (1996) Growth differentiation factor-9 is required during early ovarian folliculogenesis Nature 383 531-535

Dube JL, Wang P, Elvin J, Lyons KM, Celeste AJ and Matzuk MM (1998) The bone morphogenetic protein 15 gene is X-linked and expressed in oocytes Molecular Endocrinology 12 1809-1817

El-Fouly MA, Cook B, Nekola M and Nalbandov AV (1970) Role of the ovum in follicular luteinization Endocrinology 87 288-293

Elvin JA, Clark AT, Wang P, Wolfman NM and Matzuk MM (1999a) Paracrine actions of growth differentiation factor-9 in the mammalian ovary Molecular Endocrinology 13 1035-1048

*Elvin JA, Yan CN, Wang P, Nishimori K and Matzuk MM (1999b) Molecular characterization of the follicle defects in the growth differentiation factor 9-deficient ovary Molecular Endocrinology 13 1018-1034

Elvin JA, Yan CN and Matzuk MM (2000a) Growth differentiation factor-9 stimulates progesterone synthesis in granulosa cells via a prostaglandin E-2/EP2 receptor pathway Proceedings of the National Academy of Sciences USA $9710288-10293$

Elvin JA, Yan CN and Matzuk MM (2000b) Oocyte-expressed TGF-beta superfamily members in female fertility Molecular and Cellular Endocrinology 159 1-5

Eppig JJ (1979) FSH stimulates hyaluronic acid synthesis by oocytecumulus cell complexes from mouse preovulatory follicles Nature $\mathbf{2 8 1}$ 483-484

Eppig JJ (1991) Maintenance of meiotic arrest and the induction of oocyte maturation in mouse oocyte-granulosa cell complexes developed in vitro from preantral follicles Biology of Reproduction 45 824-830

Eppig JJ and O'Brien MJ (1996) Development in vitro of mouse oocytes from primordial follicles Biology of Reproduction 54 197-207

*Eppig JJ, Wigglesworth K, Pendola FL and Hirao Y (1997a) Murine oocytes suppress expression of luteinizing hormone receptor messenger ribonucleic acid by granulosa cells Biology of Reproduction 56 976-984

Eppig JJ, Chesnel F, Hirao Y, O'Brien MJ, Pendola FL, Watanabe S and Wigglesworth K (1997b) Oocyte control of granulosa cell development: how and why Human Reproduction 12 National Supplement Journal of the British Fertility Society 2 127-132

Eppig JJ, O'Brien MJ, Pendola FL and Watanabe S (1998) Factors affecting the developmental competence of mouse oocytes grown in vitro: follicle-stimulating hormone and insulin Biology of Reproduction 59 1445-1453

Fortune JE and Eppig JJ (1979) Effects of gonadotropins on steroid secretion by infantile and juvenile mouse ovaries in vitro. Endocrinology 105 760-768

Furman A, Rotmensch S, Kohen F, Mashiach S and Amsterdam A (1986) Regulation of rat granulosa cell differentiation by extracellular matrix produced by bovine corneal endothelial cells Endocrinology 118 1878-1885

*Galloway SM, McNatty KP, Cambridge LM et al. (2000) Mutations in an oocyte-derived growth factor gene (BMP15) cause increased ovulation rate and infertility in a dosage-sensitive manner Nature Genetics $\mathbf{2 5}$ 279-283
Gilchrist RB, Ritter LJ and Armstrong DG Mouse oocyte mitogenic activity is developmentally coordinated throughout folliculogenesis and meiotic maturation Developmental Biology (in press)

Handel MA and Eppig JJ (1997) Sexual dimorphism in the regulation of mammalian meiosis. In Current Topics in Developmental Biology: Meiosis and Gametogenesis pp 333-358 Ed. MA Handel. Academic Press, Orlando

*Hayashi M, McGee EA, Min G, Klein C, Rose UM, van Duin M and Hsueh AJ (1999) Recombinant growth differentiation factor-9 (GDF-9) enhances growth and differentiation of cultured early ovarian follicles Endocrinology 140 1236-1244

Hess KA, Chen L and Larsen WJ (1999) Inter- $\alpha$-inhibitor binding to hyaluronan in the cumulus extracellular matrix is required for optimal ovulation and development of mouse oocytes Biology of Reproduction $61436-443$

Hirshfield AN (1986) Patterns of $\left({ }^{3} \mathrm{H}\right)$ thymidine incorporation differ in immature rats and mature, cycling rats Biology of Reproduction 34 229-235

Huang EJ, Manova K, Packer AI, Sanchez S, Bachvarova $\mathbf{R}$ and Besmer $\mathbf{P}$ (1993) The murine steel panda mutation affects kit ligand expression and growth of early ovarian follicles Developmental Biology 157 100-109

Jaatinen R, Laitinen MP, Vuojolainen K, Aaltonen J, Louhio $\mathbf{H}$, Heikinheimo K, Lehtonen E and Ritvos O (1999) Localization of growth differentiation factor-9 (GDF-9) mRNA and protein in rat ovaries and cDNA cloning of rat GDF-9 and its novel homolog GDF-9B Molecular and Cellular Endocrinology 156 189-193

Joyce IM, Pendola FL, Wigglesworth K and Eppig JJ (1999) Oocyte regulation of kit ligand expression in mouse ovarian follicles Developmental Biology 214 342-353

Joyce IM, Clark AT, Pendola FL and Eppig JJ (2000) Comparison of GDF-9 and oocyte regulation of kit ligand expression in mouse ovarian follicles Biology of Reproduction 63 1669-1675

Joyce IM, Pendola FL, O'Brien MJ and Eppig JJ (2001) Regulation of prostaglandin-endoperoxidase synthase 2 (COX-2) mRNA expression in mouse granulosa cells during ovulation Endocrinology 142 3187-3197

Laitinen M, Vuojolainen K, Jaatinen R, Ketola I, Aaltonen J, Lehtonen E, Heikinheimo M and Ritvos O (1998) A novel growth differentiation factor-9 (GDF-9) related factor is co-expressed with GDF-9 in mouse oocytes during folliculogenesis Mechanisms of Development $\mathbf{7 8}$ 135-140

Lanuza GM, Fischman ML and Baranao JL (1998) Growth promoting activity of oocytes on granulosa cells is decreased upon meiotic maturation Developmental Biology 197 129-139

Latham KE, Bautista DM, Hirao Y, O'Brien MJ and Eppig JJ (1999) Comparison of protein synthesis patterns in mouse cumulus cells and mural granulosa cells: effects of follicle-stimulating hormone and insulin of granulosa cell differentiation in vitro. Biology of Reproduction $\mathbf{6 1}$ 482-492

Li R, Norman RJ, Armstrong DT and Gilchrist RB (2000) Oocyte-secreted factor(s) determine functional differences between bovine mural granulosa cells and cumulus cells Biology of Reproduction 63 839-845

Lim H, Paria BC, Das SK, Dinchuk JE, Langenbach R, Trzaskos JM and Dey SK (1997) Multiple female reproductive failures in cyclooxygenase 2deficient mice Cel/ 91 197-208

McGrath SA, Esquela AF and Lee SJ (1995) Oocyte-specific expression of growth differentiation factor-9 Molecular Endocrinology 9 131-136

Manova K, Huang EJ, Angeles M, DeLeon V, Sanchez S, Pronovost SM, Besmer SM and Bachvarova RF (1993) The expression pattern of the ckit ligand in gonads of mice supports a role for the c-kit receptor in oocyte growth and in proliferation of spermatogonia Developmental Biology 157 85-99

Motro B and Bernstein A (1993) Dynamic changes in ovarian c-kit and Steel expression during the estrous reproductive cycle Developmental Dynamics 197 69-79

Nagyova E, Vanderhyden BC and Prochazka R (2000) Secretion of paracrine factors enabling expansion of cumulus cells is developmentally regulated in pig oocytes Biology of Reproduction 63 1149-1156

Nekola MV and Nalbandov AV (1971) Morphological changes of rat 
follicular cells as influenced by oocytes Biology of Reproduction 4 154-160

Otsuka F, Yao Z, Lee T, Yamamoto S, Erickson GF and Shimasaki S (2000) Bone morphogenetic protein-15. Identification of target cells and biological functions Journal of Biological Chemistry 27539 523-39 528

Packer AI, Hsu YC, Besmer P and Bachvarova RF (1994) The ligand of the Ckit receptor promotes oocyte growth Developmental Biology 161 194-205

Pincus G and Enzmann EV (1935) The comparative behavior of mammalian eggs in vivo and in vitro I. The activation of ovarian eggs Journal of Experimental Medicine 62 655-675

Prochazka R, Nagyova E, Rimkevicova Z, Nagai T, Kikuchi K and Motlik J (1991) Lack of effect of oocytectomy on expansion of the porcine cumulus Journal of Reproduction and Fertility 93 569-576

Prochazka R, Nagyova E, Brem G, Schellander K and Motlik J (1998) Secretion of cumulus expansion-enabling factor (CEEF) in porcine follicles Molecular Reproduction and Development 49 141-149

Ralph JH, Telfer EE and Wilmut I (1995) Bovine cumulus cell expansion does not depend on the presence of an oocyte secreted factor Molecular Reproduction and Development 42 248-253

Reynaud K, Cortvrindt R, Smitz J and Driancourt MA (2000) Effects of Kit Ligand and anti-Kit antibody on growth of cultured mouse preantral follicles Molecular Reproduction and Development 56 483-494

Richards JS, Fitzpatrick SL, Clemens JW, Morris JK, Alliston T and Sirois J (1995) Ovarian cell differentiation: a cascade of multiple hormones, cellular signals, and regulated genes. In Recent Progress in Hormone Research pp 223-254 Ed. CW Bardin. Academic Press, San Diego

Salustri A, Yanagishita M and Hascall VC (1989) Synthesis and accumulation of hyaluronic acid and proteoglycans in the mouse cumulus cell-oocyte complex during follicle-stimulating hormone-induced mucification Journal of Biological Chemistry 26413 840-13 847

*Salustri A, Yanagishita M and Hascall VC (1990) Mouse oocytes regulate hyaluronic acid synthesis and mucification by FSH-stimulated cumulus cells Developmental Biology 138 26-32

Singh B, Zhang XQ and Armstrong DT (1993) Porcine oocytes release cumulus expansion-enabling activity even though porcine cumulus expansion in vitro is independent of the oocyte Endocrinology 132 1860-1862
*Soyal SM, Amleh A and Dean J (2000) FIG $\alpha$, a germ cell-specific transcription factor required for ovarian follicle formation Development 127 4645-4654

Vanderhyden BC (1993) Species differences in the regulation of cumulus expansion by an oocyte-secreted factor(s) Journal of Reproduction and Fertility 98 219-227

Vanderhyden BC (1996) Oocyte-secreted factors regulate granulosa cell steroidogenesis Zygote 4 317-321

Vanderhyden BC and Macdonald EA (1998) Mouse oocytes regulate granulosa cell steroidogenesis throughout follicular development Biology of Reproduction 59 1296-1301

Vanderhyden BC and Tonary AM (1995) Differential regulation of progesterone and estradiol production by mouse cumulus and mural granulosa cells by a factor(s) secreted by the oocyte Biology of Reproduction 53 1243-1250

*Vanderhyden BC, Caron PJ, Buccione R and Eppig JJ (1990) Developmental pattern of the secretion of cumulus-expansion enabling factor by mouse oocytes and the role of oocytes in promoting granulosa cell differentiation Developmental Biology 140 307-317

*Vanderhyden BC, Telfer EE and Eppig JJ (1992) Mouse oocytes promote proliferation of granulosa cells from preantral and antral follicles in vitro. Biology of Reproduction 46 1196-1204

Vanderhyden BC, Cohen JN and Morley P (1993) Mouse oocytes regulate granulosa cell steroidogenesis Endocrinology 133 423-426

*Vanderhyden BC and Macdonald EA (1998) Mouse oocytes regulate granulosa cell steroidogenesis throughout follicular development Biology of Reproduction 59 1296-1301

Vitt UA, Hayashi M, Klein C and Hsueh AJ (2000) Growth differentiation factor-9 stimulates proliferation but suppresses the follicle-stimulating hormone-induced differentiation of cultured granulosa cells from small antral and preovulatory rat follicles Biology of Reproduction 62 370-377

*Yan C, Wang P, DeMayo J et al. (2001) Synergistic roles of bone morphogenetic protein 15 and growth differentiation factor 9 in ovarian function Molecular Endocrinology 15 854-866

Yoshida H, Takakura N, Kataoka H, Kunisada T, Okamura H and Nishikawa S (1997) Stepwise requirement of c-kit tyrosine kinase in mouse ovarian follicle development Developmental Biology 184 $122-137$ 